\section{Utilizing a Journal Club to Build Research Competencies in a Cross-Disciplinary Environment}

\author{
Joanne Wincentak \\ Holland Bloorview Kids Rehabilitation Hospital \& University of Toronto
}

Stephanie Cheung

Bloorview Research Institute \& University of Toronto

Shauna Kingsnorth

Holland Bloorview Kids Rehabilitation Hospital \& University of Toronto

\begin{abstract}
Background The goal of this process-focused field note is to detail the steps taken to design and implement the pilot of a cross-disciplinary research-trainee-led journal club within a hospital-based research institute.
\end{abstract}

Analysis The journal club was designed to support learning goals in the areas of critical appraisal, research knowledge, and communication within a cross-disciplinary environment. The evaluation data for the three pilot sessions are presented, and successes and challenges are discussed.

Conclusion and implications Recommendations for institutes interested in the implementation of similar programs focused on research competencies within a cross-disciplinary setting are given.

Keywords Knowledge dissemination; Tools and practices; Journal club; Research training; Interdisciplinary communication; Program development

\section{Résumé}

Le but de cette note de terrain est de détailler les étapes de la conception et exécution du pilote d'un club de lecture scientifique interdisciplinaire dirigé par des étudiants au sein d'un institut de recherche en milieu hospitalier. Le club de lecture a été conçu pour soutenir des objectifs d'apprentissage relevant des domaines de l'analyse critique, du savoir, et de la communication de recherche au sein d'un environnement interdisciplinaire. Les données d'évaluation pour les trois sessions pilotes sont présentées dans cet article et les succès et défis discutés. Des recommandations sont

\section{CISP Press}

Scholarly and Research Communication

Volume 10, Issue 3, Article ID 0305337, 16 pages

Journal URL: www.src-online.ca http://doi.org/10.22230/src.2019v10n3a337

Received December 19, 2018, Accepted April 10, 2019, Published June, 17, 2019

Wincentak, Joanne, Cheung, Stephanie, \& Kingsnorth, Shauna. (2019). Utilizing a Journal Club to Build Research Competencies in a Cross-Disciplinary Environment. Scholarly and Research Communication, 10(3): 0305337, $16 \mathrm{pp}$.

(C) 2019 Joanne Wincentak, Stephanie Cheung, \& Shauna Kingsnorth. This Open Access article is distributed under the terms of the Creative Commons Attribution Non-Commercial License (http:// creativecommons.org/licenses/by-nc-nd/2.5/ca), which permits unrestricted non-commercial use, distribution, and reproduction in any medium, provided the original work is properly cited.
Joanne Wincentak is a Knowledge Broker in Evidence to Care at Holland Bloorview Kids Rehabilitation Hospital and a Status-Only Lecturer in the Department of Occupational Science and Occupational Therapy, University of Toronto, 150 Kilgour Road, Toronto, ON, M4G 1R8. Email: jwincentak @hollandbloorview.ca

Stephanie Cheung is a $\mathrm{PhD}$ candidate at Holland

Bloorview Kids Rehabilitation Hospital and the Institute of Biomaterials and Biomedical Engineering, University of Toronto, 150 Kilgour Road, Toronto, ON, M4G 1 R8.

Email: scheung

@hollandbloorview.ca

Shauna Kingsnorth is the Manager of Evidence to Care at Holland Bloorview Kids Rehabilitation Hospital and an Assistant Professor in the Department of Occupational Science and Occupational Therapy, University of Toronto, 150 Kilgour Road, Toronto, ON, M4G 1 R8. Email: skingsnorth @hollandbloorview.ca 


\section{Scholarly and Research}

Communication

VOLUME 10 / ISSUE $3 / 2019$ faites pour les instituts intéressés par l'exécution de programmes similaires axés sur des compétences de recherche dans un cadre interdisciplinaire.

Mots clés Knowledge dissemination: Tools and practices; Journal club; Research training; Interdisciplinary communication; Program development

\section{Introduction}

This process-focused field note discusses the design and implementation of a cross-disciplinary journal club, targeting competency building in a childhood health-oriented research institute. The aim is to provide a step-by-step outline, recommendations, and evaluation data for other cross-disciplinary institutes with an interest in journal clubs as a competency-building tool for research trainees. This work is situated within a healthcare context.

\section{Setting The Stage: Defining CROSS-Disciplinary interaction}

Within this article, the terms interprofessional research lab/centre and cross-disciplinary interaction are used. The term interprofessional research lab/centre denotes a team that comprises two or more individuals with differing specialized practice knowledge (e.g., occupational therapy, engineering, neuroscience) who work together to address research questions within the same research field. Cross-disciplinary interaction captures the interaction between researchers from two or more research fields (i.e., academic areas of study) within the same research discipline. For example, childhood disability is a research discipline that can be further narrowed into more specific research fields, such as social development in children with disabilities, motor skill evaluation, post-injury recovery, and therapeutic technology.

\section{Literature review}

\section{RESEARCHER COMPETENCIES}

Competency is broadly defined as a combination of skills, knowledge, and attitude. Researcher competence is critical for robust, impactful research with meaningful outcomes for stakeholders. A number of publications within health sciences (Burgess, Menachemi, \& Maciejewski, 2018; Stucki, 2007), public health (Calhoun, McElligott, Weist, \& Raczynski, 2012; Ryan, Yeung, Bass, Kapil, Slater, \& Creedon, 2012; Sawleshwarkar \& Negin, 2017), and biomedical (Barnett, Harris, \& Mulvany, 2017; Smith, Jarrett, \& Bierer, 2013; Wang, Power, Kahler, Lyras, Young, Iredell, \& Robins-Browne, 2018) literature have discussed the breadth of competencies required by researchers. Research trainees at the master's, doctoral, and postdoctoral levels are expected to demonstrate evidence of accomplishing these competencies (Burgess et al., 2018; Verderame, Freedman, Kozlowski, \& Mccormack, 2018), which are described below.

There are several competencies in statistical, technical, and theoretical knowledge application that are research discipline specific. However, many competencies essential to success as a researcher are common to most research fields (Verderame et al., 2018). Teamwork and collaboration, broad conceptual knowledge of the research discipline, comprehensive understanding of their research field, communication, critical thinking, research design, research ethics, and knowledge transfer (Burgess et al., 2018; Verderame et al., 2018) have all been identified as core competencies for researchers. Due to the inherent complexity of health issues, there is also an increasing importance 
in openness and the capacity for cross-disciplinary work within health research (Burgess et al., 2018; Godley, Glenn, Sharma, \& Spence, 2014). There is, however, a paucity of scholarly literature focused on the development and implementation of practical strategies for research trainee competency building.

\section{JOURNAL CLUBS AS A COMPETENCY BUILDER}

Journal clubs are gatherings of peers who read and discuss scholarly research publications of professional interest. One of the first documented descriptions of a journal club was from Sir James Paget at St. Bartholomew's Hospital in London, England, between the years 1835-1854 (Lizner, 1987). Within this setting, the journal club was used a tool for reading and discussing journals, as well as a forum to connect socially with peers. However, William Osler while at McGill University in Montreal, Canada is credited with popularizing journal clubs, as many followed his format. His journal club was structured to be medical speciality-specific, where the primary goal was to encourage reading and critiquing scholarly literature. At the heart of this structure was a casual atmosphere that fostered discussion (Topf, Sparks, Phelan, Shah, Lerma, Graham-Brown, Hadariaga, Iannuzzella, Rheault, Oates, Jhaveri, \& Hiremath, 2017). Journal clubs gained traction within medical education for residents and continuing education for doctors throughout the 1900s (Lizner, 1987).

The clinical uptake and goals of journal clubs have since evolved. Within the current literature, journal clubs are primarily used for continuing education among clinicians such as doctors, nurses, and allied health professionals (Topf et al., 2017; van Diggele, Burgess, \& Mellis, 2018). Journal clubs have facilitated the self-reported attainment of goals related to keeping up to date with best clinical practice, critical appraisal, evidence-based practice (Dall'Oglio, Vanzi, Tiozzo, Gawronski, Biagioli, Tucci, \& Raponi, 2018; Gottlieb, Kin, Byyny, Parsons, \& Bailitz, 2018), as well as increased competence in conducting research (Dall'Oglio et al., 2018).

When compared to clinical literature, there is relatively little describing the value of journal clubs as competency builders among researchers. A notable exception is the research methods-focused journal club led by Susan Vadaparampil and colleagues (2014). They implemented a journal club about community-based participatory research that was open to all researchers (i.e., trainees, scientists, staff) and community members within the Moffitt Cancer Centre in Tampa, Florida. Researchers reported enhanced knowledge of research methods and connections to the community.

Narrowing the focus: Cross-disciplinary interaction through journal clubs for research trainee competency building

Studies show the value of facilitating interactions between researchers from different research fields within a discipline (Hills \& Richards, 2014; Ryan et al., 2012). Bringing a cross-disciplinary group of researchers together can be a catalyst for enhanced learning. There is an opportunity for researchers to learn about different epistemological views, methodologies, and/or approaches to address research questions, which they can apply and potentially strengthen their future work. Additionally, researchers develop respect for different disciplines, develop communication skills, and identify the strengths and limitations of their own discipline through cross-disciplinary interac-

Wincentak, Joanne, Cheung, Stephanie, \& Kingsnorth, Shauna. (2019). Utilizing a Journal Club to Build Research Competencies in a Cross-Disciplinary Environment. Scholarly and Research Communication, 10(3): 0305337, $16 \mathrm{pp}$. 


\section{Scholarly and Research}

Communication

VOLUME 10 / ISSUE $3 / 2019$ tions (Carr, Loucks, \& Blöschl, 2018). Strategies identified by Gemma Carr, Daniel Loucks, and Günter Blöschl (2018) to promote cross-disciplinary interaction include shared work spaces, compulsory courses, seminar series, and joint supervision.

Within the weight-related research discipline, Jenny Godley, Nicole M. Glenn, Arya M. Sharma, \& John C. Spence (2014) demonstrated the value of a seven-day intensive cross-disciplinary training camp for 24 research trainees led by the Canadian Obesity Network. The camp was structured around networking exercises, two lectures per day, and journal club sessions. Trainee attendees were from medicine, basic science, kinesiology, nutrition, and social sciences research fields. Attendees expressed that the crossdisciplinary nature of camp deepened their knowledge about the research discipline. It also prompted some trainees to incorporate new research practices/methods to expand upon their current work within their own research field.

Although effective, the competence-building strategies put forward by Carr et al. (2018) and journal club formats described by Vadaparampil et al. (2014) and Godley et al. (2014) are resource intensive. Executing these strategies would not be feasible within most research institute settings, where the responsibility for competency-building activities outside of the scientist-trainee relationship is held by the trainees themselves.

Based on these literature findings, feasibility, and capacity factors, Holland Bloorview Kids Rehabilitation Hospital's research institute's trainee-led professional development group identified journal clubs as a potential cross-disciplinary competency-building tool.

\section{Research context}

The Bloorview Research Institute is integrated into Holland Bloorview Kids Rehabilitation Hospital, an academic teaching hospital with expertise in childhood disability, rehabilitation, and health. The Bloorview Research Institute houses 270 researchers, where over 80 members are trainees (i.e., master's students/candidates, $\mathrm{PhD}$ students/candidates, and postdoctoral fellows). Research is conducted within 12 interprofessional research centres/labs, and addresses research questions from diverse and distinct research fields. Examples include psychosocial well-being, physical function, assistive technology, transitions, neuroimaging, and critical disability studies.

The Bloorview Research Institute Trainee Executive (BRITE) is a trainee-led initiative that works in partnership with the Bloorview Research Institute to focus on the professional needs of trainees. Two co-chairs, a communications chair, an academic chair, a professional development chair, a "trainee life" chair, a finance chair, and an events chair operate the trainee group. Their mandate is to create a community that provides opportunities for academic growth, peer support, and collaboration. Therefore, the design and delivery of competence-building opportunities is a priority. The Bloorview Research Institute also has a dedicated knowledge translation team (Evidence to Care), embedded within the Teaching and Learning Institute, which promotes the sharing and uptake of research (Kingsnorth, Orava, Parker, \& Milo-Manson). BRITE and Evidence to Care have a history of partnerships focused on delivering research trainee competency building opportunities. 


\section{Cross-disciplinary journal club design and implementation pilot process}

This cross-disciplinary journal club is a joint initiative by BRITE and Evidence to Care The following section is a step-by-step account of the design and implementation process. Table 1 provides an outline of the steps.

\section{Table 1: Summary of the design and implementation pilot process}

Step 1 Securing decision maker buy-in

Step 2 Developing a needs assessment

Step 3 Evaluating needs assessment responses

Step 4 Finalizing journal club aims and format

Step 5 Designing a post-session evaluation

Step 6 Implementing and planning for sustainability

\section{STEP 1: SECURING DECISION MAKER BUY-IN}

BRITE receives funding and the approval of activities from the Vice President of the Bloorview Research Institute. Therefore, a proposal for a three-month journal club pilot was submitted to illustrate how a journal club advances the institute's strategic aims and benefits the learning experience of research trainees. With buy-in and the endorsement of the pilot by the Vice President, the authors were able to move forward with next steps.

\section{Step 2: Developing a NeEds ASSESSMent}

A needs assessment was undertaken to gauge the interest of Bloorview Research Institute members in the journal club. A survey was created to determine 1) the roles of interested research members, 2) learning goals, and 3) research topics of interest.

\section{Roles}

To ascertain whether there was cross-disciplinary interest in a cross-disciplinary journal club, respondents were asked to indicate their role within the Bloorview Research Institute.

\section{Learning goals}

A literature review on effective journal clubs (Deenadayalan, Gimmer-Somers, Prior, \& Kumar, 2008) and the authors of this field note informed the learning goals put forward in the needs assessment. Checkbox responses were used so that respondents could indicate all that applied. These goals included

1. Learn about research methodologies/ paradigms

2. Review childhood disability research

3. Develop critical appraisal skills

4. Network with Bloorview Research Institute members

5. Build communication skills

6. Improve research literacy

7. Other (open text box) 


\section{Scholarly and Research}

\section{Communication}

VOLUME 10 / ISSUE 3 / 2019

\section{Research topics of interest}

Journal club best practices outline that articles discussed in a journal club should be of interest to all attendees and in line with the journal club's goals (Deenadayalan et al., 2018). Given the diversity of research fields housed within the Bloorview Research Institute, considerable thought was put into finding a common research topic of interest to potential attendees. The authors postulated that framing the journal club around methodologies/paradigms within childhood disability research would be of mutual interest. The BRITE co-chairs, BRITE academic chair, and a research trainee vetted this decision. Within the needs assessment, the methodologies/paradigms of greatest interest were explored.

For the learning goals and methodologies/paradigms, respondents selected all that applied and were also permitted to identify their own. Respondents were also asked about date and timing for the journal club.

\section{STEP 3: Evaluating NEEDS ASSESSMENT RESPONSES}

With the goal of nurturing an inclusive, open, cross-disciplinary environment, the needs assessment was sent to all Bloorview Research Institute members (outlined below). A five-minute web-based survey was sent to all 270 members through an internal email list.

Roles

Respondents were trainees $(N=18)$, research staff $(N=14)$, scientists $(N=7)$, clinicians $(N=6)$, administrative/operations staff $(N=3)$, and knowledge translation staff $(N=1)$, as shown in Figure 1. Respondents were able to select all of the roles that applied to them.

\section{Figure 1: Role distribution of research institute members interested in attending journal club}

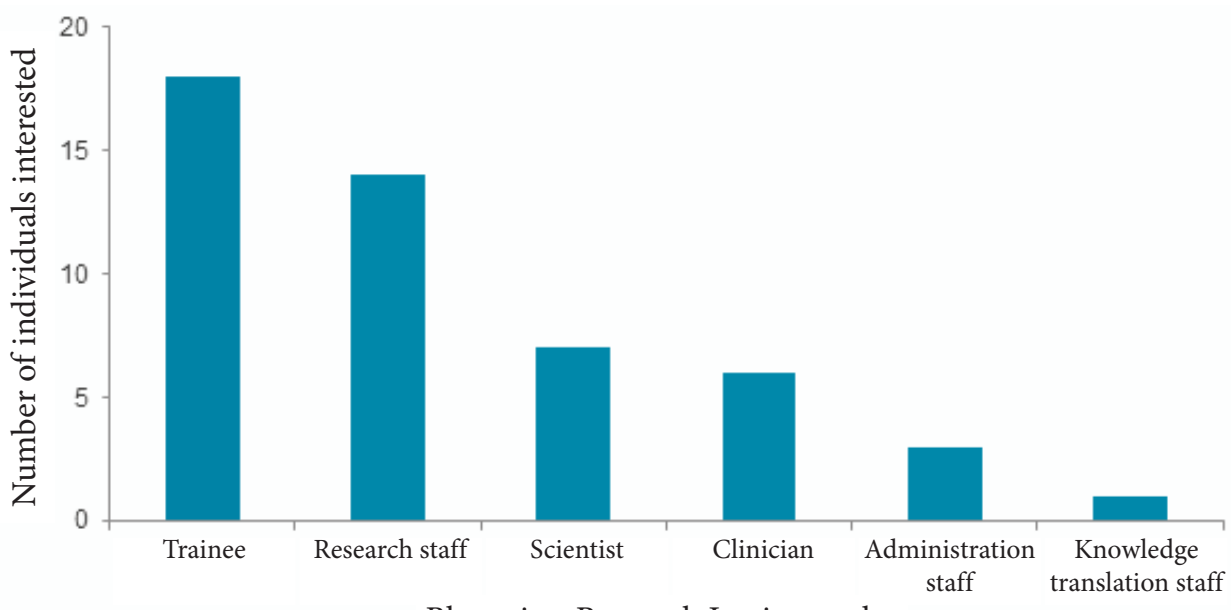

Bloorview Research Institute roles

The needs assessment had a 16.7 percent response rate $(45 / 270)$. Of the 45 respondents, 95.5 percent $(42 / 45)$ indicated that they were interested in participating in a cross-disciplinary journal club. In comments, some respondents identified the potential net-

Wincentak, Joanne, Cheung, Stephanie, \& Kingsnorth, Shauna. (2019). Utilizing a Journal Club to Build Research Competencies in a Cross-Disciplinary Environment. Scholarly and Research Communication, 10(3): 0305337, $16 \mathrm{pp}$. 
working value of the program for trainees in smaller research labs/centres (e.g., labs with less than five people). Based on this response, proceeding with a three-month pilot was determined worthwhile.

\section{Learning goals}

As mentioned above, the needs assessment endorsed a total of six interconnected learning goals:

1. Learn about research methodologies/paradigms

2. Review childhood disability research

3. Develop critical appraisal skills

4. Network with Bloorview Research Institute members

5. Build communication skills

6. Improve research literacy

The majority of respondents, 76.2 percent, expressed an interest in learning about research methodologies/paradigms, which validated the decision to focus on this area within the journal club. Further, 73.5 percent identified a learning goal to review childhood disability research and 38.1 percent identified a learning goal to improve research literacy. These three learning goals are all areas of broad conceptual knowledge in childhood disability research. An interest in critical appraisal was also identified (50.0\%). Finally, research communication emerged as a key competence objective: respondents reported interest in professional networking (47.6\%) and building communication skills (40.5\%). The initial design of the journal club was focused around the six learning goals. The pilot took an iterative approach to design, framing the structure and discussion questions around three distilled competence objectives: conceptual knowledge, critical appraisal, and communication (see Figure 2).

Figure 2: Learning goals organized into three overarching competency areas
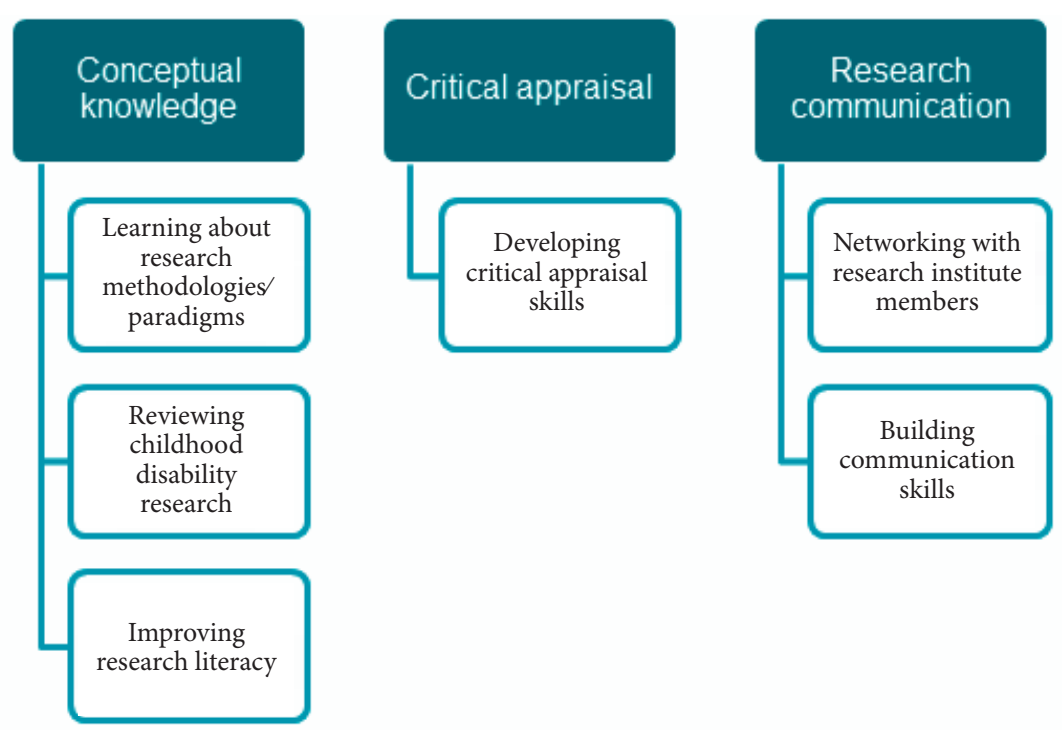

Research topics of interest

The three methodologies/paradigms of the greatest interest to survey respondents were systematic reviews (65.9\%), pilot/feasibility studies (63.4\%), and critical qualitative the-

Wincentak, Joanne, Cheung, Stephanie, \& Kingsnorth, Shauna. (2019). Utilizing a Journal Club to Build Research Competencies in a Cross-Disciplinary Environment. Scholarly and Research Communication, 10(3): 0305337, $16 \mathrm{pp}$. 


\section{Scholarly and Research}

Communication

VOLUME 10 / ISSUE $3 / 2019$ ory $(61.0 \%)$. Other research topics of interest included randomized controlled trials (58.5\%), implementation science (58.5\%), and scoping reviews (51.2\%). The three topics of greatest interest were therefore chosen as topics for the three pilot journal club sessions in order to draw the greatest interest from potential attendees in the pilot stage. Although the response to the program proposal was largely positive, one respondent commented on the potential difficulty of finding topics of mutual interest within an interprofessional and cross-disciplinary group.

\section{STEP 4: FINALIZING CROSS-DISCIPLINARY JOURNAL CLUB AIMS AND FORMAT}

In line with the goals to connect researchers across disciplines and build competency in broadly and mutually relevant areas, the journal club was aimed to be methodology/paradigm-focused. Therefore, emphasis was placed on selecting peer-reviewed articles in line with the common methods and paradigms in childhood disability research endorsed in the needs assessment.

The format of the journal club was guided by reported best practices and the authors' experiences. The journal club was set to occur for one hour on a monthly basis with the following components:

1. One designated facilitator: the session should be trainee-led and open with a 15-minute reading summary presented by a trainee.

2. Critical appraisal through discussion: a guided discussion period should follow the summary presentation.

3. Circulate the article ahead of time: to optimize discussion, the article was sent to the journal club one week prior to the meeting to ensure attendees could review the content.

4. Evaluate outcomes: a post-session evaluation was used to monitor the value-add of the session.

\section{Step 5: Designing a POST-Session evaluation}

In line with best practices, the team decided to evaluate the journal club on an ongoing basis through post-session evaluation forms. The design was reviewed by members of Evidence to Care with expertise in program evaluation. These evaluations were distributed to journal club attendees in the last five minutes of each journal club.

For session one, respondents were asked to note their role within the research institute on the evaluation form. For sessions two and three, this question was replaced with a question about the number of previous journal clubs in which they had participated. This change was made out of concern that participants may be hesitant to associate critical feedback with their role on an evaluation form with fewer than 20 respondents, from which their identities might be determined.

Broadly, the evaluation form was designed to gather information about the value and fit of the journal club and to identify components that are important or missing. Respondents were asked to indicate whether participating in the journal club session contributed to any of the six learning goals identified in the needs assessment. The extent (i.e., strongly agree to strongly disagree) to which the content was aligned with 
the most commonly identified learning goals was explored. The suitability of the journal club structure was also evaluated. The evaluation provided attendees with the opportunity to identify the single most valuable part of the journal club session, in addition to suggestions for improvement. To identify how learning goals were enhanced for the trainee presenter, a series of open-ended questions was posed through email following their session. These questions were designed to determine the benefit of leading the session and to identify areas for improvement.

The aggregate results of this evaluation are intended to inform whether or not to move forward with the journal club. Pilot test indicators for success included attendance, favourable responses on the evaluation forms, and the observed level of attendee engagement during the session.

\section{STEP 6: IMPLEMENTING AND PLANNING FOR SUSTAINABILITY}

To ensure sustainability, the first author and the second author acted as program facilitators; this involved being points of contact for each trainee presenter during the weeks leading up to their session. Trainees were invited to lead sessions through the research institute trainee mailing list, through scientists, and in person. Program facilitators worked individually with presenters to choose an article in line with their interests. The program facilitators provided presenters with suggested articles based off of quick literature searches on the designated research methods/paradigm topic.

Trainee presenters were encouraged to formulate discussion questions based on what they felt were the strengths and weaknesses of the article (critical appraisal). The program facilitators were present at each session to provide support for the trainee presenters and to offer prompts during the discussion period where needed.

Three journal club pilot sessions were pre-scheduled over a three-month window. Meeting invites were sent through the research institute's mailing list two weeks before the scheduled session.

\section{Evaluation results}

The following section summarizes the post-session evaluation results based on the feedback of 22 attendees across the three sessions and the three trainee presenters.

\section{ROLES AND ATTENDANCE}

Advertising the journal club event led to interest from clinicians and family leaders who were forwarded meeting invites.

Family leaders are family members of current or past clients who support hospital and research projects as community members. While the journal club was originally envisioned to cater specifically to the learning goals and research topics of interest to researchers, the session was open to anyone interested. However, messaging about the journal club emphasized its strong research focus. While information about attendees' roles in the research institute was not gathered past the first session, it was apparent that attendees represented all roles at the research institute except for administrators/ operations staff. The reach of this program was broader than initially anticipated.

Wincentak, Joanne, Cheung, Stephanie, \& Kingsnorth, Shauna. (2019). Utilizing a Journal Club to Build Research Competencies in a Cross-Disciplinary Environment. Scholarly and Research Communication, 10(3): 0305337, $16 \mathrm{pp}$. 


\section{Scholarly and Research}

\section{Communication}

VOLUME 10 / ISSUE 3 / 2019
Excluding the trainee presenter and two facilitators, nine attendees were present at the first session, 11 at the second session, and five at the third session. Post-session evaluation response rates were 89 percent $(8 / 9), 82$ percent $(9 / 11)$, and 100 percent $(5 / 5)$ for session one, two, and three, respectively. Three attendees of the first journal club session also attended the second journal club session. Two attendees participated in all three pilot sessions of the journal club. Given the level of engagement, this met the criteria for the pilot to be viable moving forward.

\section{Attendee feedback}

\section{Learning goals}

Of the learning goals outlined on the session feedback survey, attendees most often reported that the journal club contributed to their goals of learning about specific methodologies, reviewing childhood disability research, and developing critical appraisal skills (see Figure 3). The former two goals are important aspects of competency in conceptual knowledge. Attendees identified the competence area of communication as the goal that was the least developed by participation in journal club. This is not surprising; while trainee presenters had the opportunity to develop communication through a rehearsed presentation, the opportunity for attendees to develop this competence area was through the discussion period. However, this component was designed to facilitate idea sharing and critiquing, rather than specific skill building in communication or networking.

Figure 3: The percentage of attendees who indicated the proposed learning goals were met

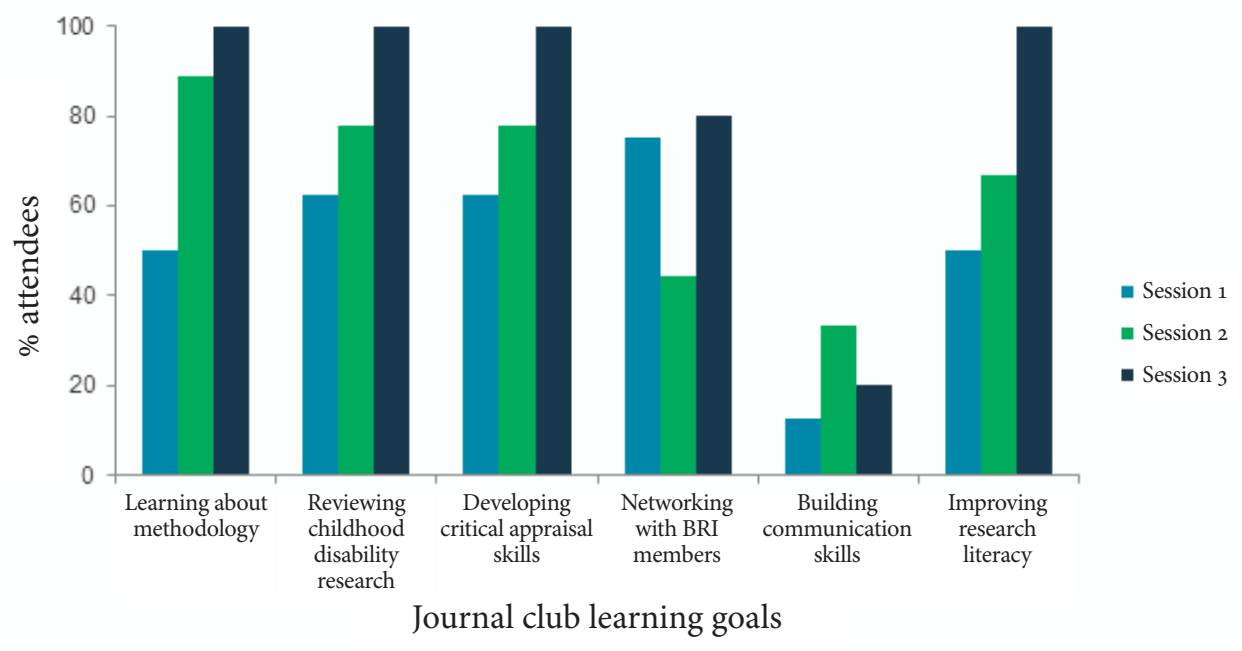

\section{Content}

For the journal club content, learning goals most commonly identified in the needs assessment were prioritized as the focus. Figure 4 shows the percentage of responses that agreed (strongly agree or agree) with statements pertaining to satisfaction with the content of the journal club sessions. Attendees' satisfaction with the content of the journal club session varied between the first session and the latter two. In sessions two and three, respondents were largely satisfied with the use of discussion questions to facilitate research method/paradigm learning and to support critical appraisal. Respondents 
were overall less satisfied with these aspects in session one. The difference in rating might be attributed to the changes made to address feedback and clarify the journal club's objectives. Respondents expressed agreement with the statement that the articles discussed contributed to their knowledge of childhood disability research in sessions two and three.

Figure 4: Percentage of attendees in agreeance with questions related to journal club content

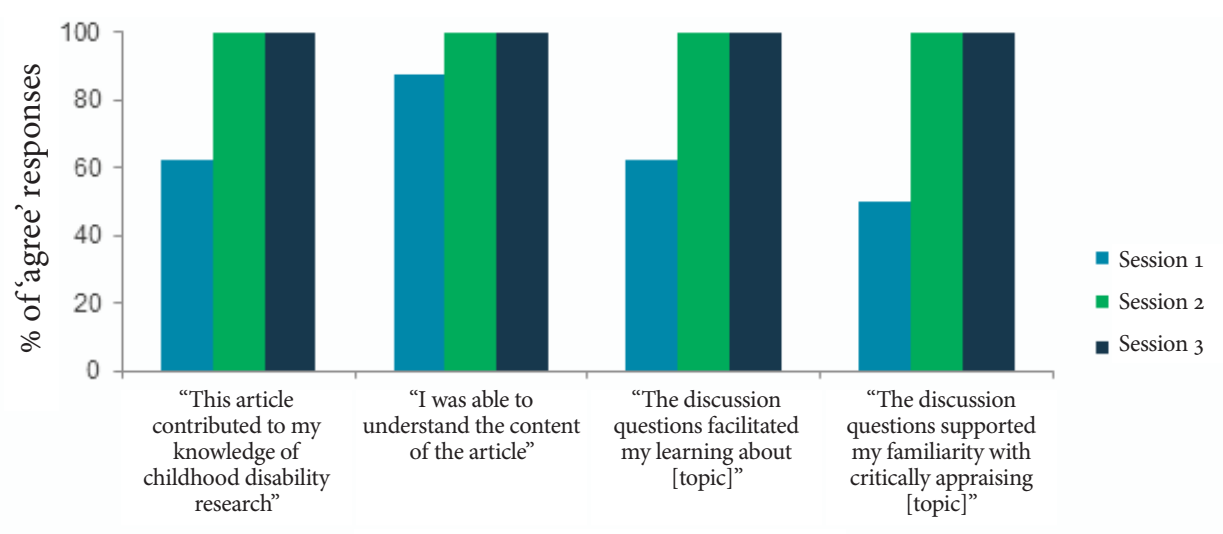

Journal club content

\section{Format}

Responses to prompts regarding the format of the journal club revealed most attendees agreed (strongly agree or agree) that a one-hour session was appropriate, the traineeled presentation was valuable, there was enough time for guided discussion, and the trainee was effective in guiding the discussion (see Figure 5). These findings indicate a good fit of the journal club with attendees.

Figure 5: The percentage of respondents in agreeance with questions related to journal club format

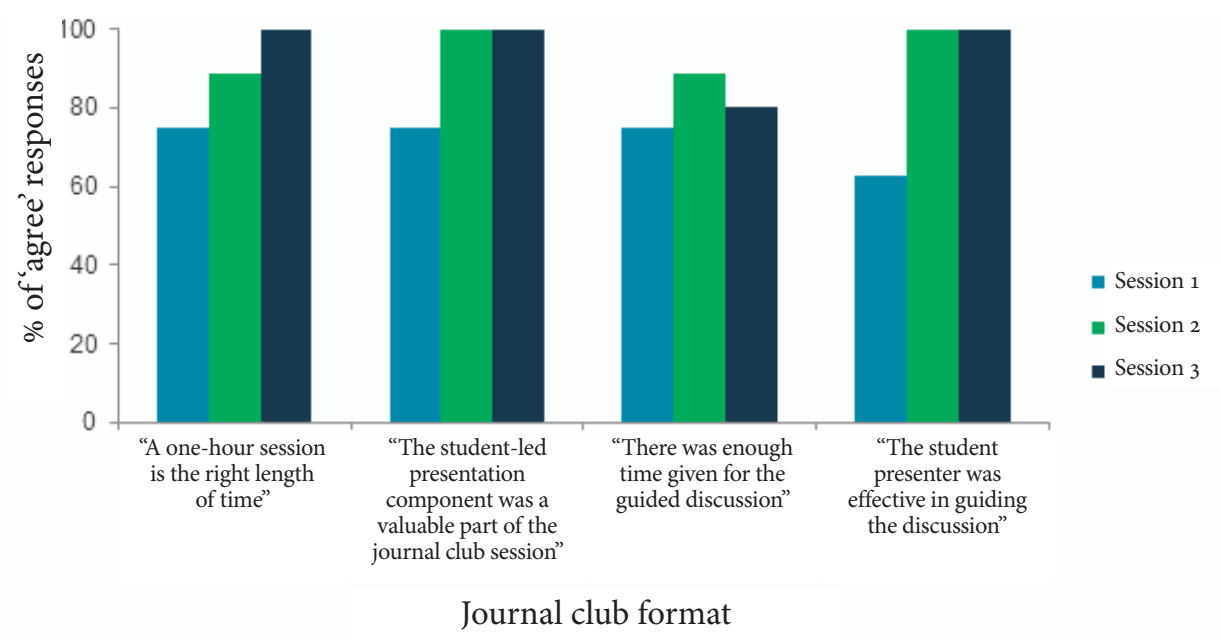

In the open-answer portions of the survey, respondents commonly noted that the discussion portion of the journal club was the most valuable ( 12 of 22 responses). Of note, 


\section{Scholarly and Research}

Communication

VOLUME 10 / ISSUE 3 / 2019 seven participants said that the emphasis on critical appraisal was appreciated, while five participants valued developing their content knowledge. Suggestions for improving the journal club included lengthening the time of the sessions (two respondents), clarifying its structure and objectives (two respondents), topics for future sessions (two respondents), and shortening the student presentation (one respondent).

\section{TRAINEE PRESENTER FEEDBACK}

While a very small number, all three trainee presenters expressed satisfaction with presenting at the journal club and participating in the discussion. The trainee-led format lends itself well to the development of trainees' research competencies.

\section{Conceptual knowledge}

One presenter commented that the experience contributed to gaining knowledge of previously unfamiliar research methods: "Leading the session pushed me to look up pilot/feasibility methodology." Another presenter noted that the journal club format introduced new research concepts: "[Journal club] encourages me to read articles that I wouldn't normally read, as they might be outside my area of interest."

\section{Critical appraisal}

One trainee presenter noted: "[facilitating the journal club] forces you to critically appraise an article more thoroughly, which leads me to consider details about their methods and rationale for the study more closely than I typically would if I were not presenting." Another presenter acknowledged that the discussion format contributed to this competency area: "Given that individuals in the room came from different backgrounds, it was neat to hear the different perspectives that were brought to the table. I think it helped to improve my critical appraisal skills after hearing others point out some key flaws in the authors' study design, methodology, conclusions, etc. which I can hopefully also incorporate into my own research.”

\section{Communication}

Presenters expressed that the experience of facilitating a journal club session helped them practice communicating research findings to their audience. One trainee noted: "[Facilitating journal club] enhanced my knowledge translation skills, especially since the audience was a mixture of researchers and lay people and my task was to deliver the presentation in a way that was meaningful to everybody." Another trainee also commented that "[It was] also great to have the opportunity to practice any sort of presentation/facilitation in a friendly environment." The presence of community members outside of the research institute was appreciated: "[Having community members present] pushes us to answer questions that we might take for granted."

\section{Lessons learned, recommendations, and reflections}

The journal club pilot was largely successful and appears to be a viable approach for facilitating cross-disciplinary interaction and addressing the competency objectives of research trainees, staff, and community members. This diversity of attendees may be a reflection of an overarching increased interest in thinking critically about research, research literacy, and engagement. Overall, attendees reported that the journal club enhanced competency in the six interrelated learning goals that, after the pilot, were 
distilled into the competency areas of conceptual knowledge, critical appraisal, and communication.

The following recommendations are for other organizations keen to develop and implement a cross-disciplinary journal club.

\section{FoCUS SESSION CONTENT ON RESEARCH METHOdOLOGIES/ PARADIGMS OF CROSS-DISCIPLINARY INTEREST}

It was found that the broad focus on common research methodologies was a strength of the design. This approach allowed a cross-disciplinary group to come together to engage in discussion. The implementation of a needs assessment was integral to the success of the pilot program, as it verified the value of this approach as well as the research methodologies/paradigms of greatest interest. Using research methods to stimulate discussion has also been previously endorsed within journal club literature (Gottlieb et al., 2018; Vadaparampil et al., 2014). It is recommended that institutions use this approach if seeking to establish a similar program. A method focus will be retained for this journal club program, and evaluations will be used as required to ensure that sessions continue to align with the interests of the cross-disciplinary group.

\section{Promote Cross-Disciplinary interaction by PRIORITIZING DISCUSSION}

The cross-disciplinary nature of the journal club enhanced trainee presenters' communication skills and enabled critical appraisal to be exercised. Presenters and attendees felt that discussion was enriched by the cross-disciplinary nature of the journal club. Furthermore, the evaluations showed that discussion was often perceived as the most important aspect of journal club. The presence of trainees from different research labs/centres and attendees affiliated with the research institute brought different perspectives and insights relevant to research. It was during discussions that attendees had the opportunity to critique, ask questions, and learn from one another. A next step is to consider how to involve clinicians and family leaders who may have insight on the content, clinical applications, and intervention acceptability of new research articles.

Multiple attendees suggested that a longer discussion would be of value. In the future, the trainee-led reading summary will be shortened to 10 minutes, allowing more time to be allocated to the discussion component. Due to scheduling challenges, accommodating this feedback by simply lengthening the duration of the session beyond one hour is not possible. However, it is encouraging that this journal club format is able to generate conversation and has the potential to lead to networking and collaboration outside of the journal club itself. In comparison to other strategies, such as shared work spaces and compulsory courses (Carr et al., 2018), journal clubs are a low-resource and easily implementable means for encouraging cross-disciplinary interaction.

\section{Focus on RESEARCH TRAINEE COMPETENCIES}

The design and implementation of this journal club was an iterative process. In analyzing what attendees valued most, literature specific to trainee competency building (Verderameet al, 2018), and organizer reflections, it became clear that the learning goals endorsed by attendees can be distilled into three overarching research competen-

Wincentak, Joanne, Cheung, Stephanie, \& Kingsnorth, Shauna. (2019). Utilizing a Journal Club to Build Research Competencies in a Cross-Disciplinary Environment. Scholarly and Research Communication, 10(3): 0305337, 16 pp. 


\section{Scholarly and Research}

\section{Communication}

VOLUME 10 / ISSUE 3 / 2019 cies. Using this lens is useful for determining the structure and focus of journal club components. Linking learning goals to competency objectives makes the intention and relevance of journal club components explicit. For example, moving forward with this lens, guiding questions for the discussion can be revised to align more closely with the conceptual knowledge competency (e.g., for those not within the articles' research field, how might it be connected to your work?). This journal club will integrate a greater emphasis on competency.

\section{Provide supports for trainee presenters}

Participants appreciated the expertise, knowledge, and guidance of the trainee presenter. By providing presenters with clear expectations and support, they were well prepared to lead their journal club session. Preparation for the trainee presenter was not insignificant, but organizers attempted to ease the workload by providing trainees with articles to choose from and additional support when needed. Trainee presenters' own competency was enhanced through the preparation and facilitation of journal club sessions. They appreciated this assistance and reported satisfaction with the level of support offered. However, not all teams may be equipped to provide the time and resources recommended.

\section{Challenges}

The journal club was not without logistical issues in this pilot phase. Preferred dates and times for sessions were collected as part of the needs assessment. However, the level of interest in attendance prior to each session was higher than the actual attendance rate. Although 42 of the 45 needs assessment respondents indicated that they were interested in the journal club, attendance ranged from five to 11 participants per session. This suggests that better communication regarding the worth of an hour spent at journal club to busy attendees with competing responsibilities is needed. The offered times will also be revisited.

Focusing on methods was a well-suited approach within a cross-disciplinary journal club; however, selecting articles still posed challenges. Accommodating the need for an article that was not overly technical or narrowly focused within a research field was difficult. Time needs to be invested in the article-selection process, while acknowledging that finding a "perfect article" that meets the interests of every attendee is unlikely.

While journal club sessions themselves are a one-hour investment, preparing for discussion may have demanded more time. Participants were encouraged to read the research article, although this was not required as the trainee presenter would provide a summary. At times, a lack of familiarity with the article content detracted from the conversation. Moving forward, stronger messaging on the expectation of reading the article will be used.

\section{Conclusion}

In this field note, the rationale, process, evaluation outcomes, and recommendations for implementing a cross-disciplinary journal club are presented. The process undertaken to design this journal club assured that the attendees' goals were targeted. The hope is that this field note illustrates the value of cross-disciplinary interaction through journal

Wincentak, Joanne, Cheung, Stephanie, \& Kingsnorth, Shauna. (2019). Utilizing a Journal Club to Build Research Competencies in a Cross-Disciplinary Environment. Scholarly and Research Communication, 10(3): 0305337, $16 \mathrm{pp}$. 
clubs within a research institute. Ultimately, the goal for this program is that it becomes self-sustaining, continues to build research competencies, and achieves an optimal balance of low effort and high reward.

\section{Acknowledgements}

The authors would like to thank the Holland Bloorview Kids Rehabilitation Hospital Foundation for funding Evidence to Care and the Bloorview Research Institute for the funding of the Bloorview Research Institute Trainee Executive. Thanks also goes to Fanny Hotzé for the French translation of the abstract.

\section{References}

Barnett, Joey, Harris, Robert, \& Mulvany, Michael. (2017). A comparison of best practices for doctoral training in Europe and North America. FEBS Open Bio, 7(10), 1444-1452.

Burgess, James, Menachemi, Nir, \& Maciejewski, Matthew. (2018). Update on the health services research doctoral core competencies. Health Services Research, 53(2), 3985-4003.

Calhoun, Judith, McElligott, John, Weist, Elizabeth, \& Raczynski, James. (2012). Core competencies for doctoral education in public health. American Journal of Public Health, 102(1), 22-29.

Carr, Gemma, Loucks, Daniel, \& Blöschl, Günter. (2018). Gaining insight into interdisciplinary research and education programmes: A framework for evaluation. Research Policy, 47(1), 35-48.

Dall'Oglio, Immacolata, Vanzi, Valentina, Tiozzo, Emanuela, Gawronski, Orsola, Biagioli, Valentina, Tucci, Serena, \& Raponi, Massimiliano. (2018). Five years of journal clubs with pediatric nurses and allied health professionals: A retrospective study and satisfaction survey. Journal of Pediatric Nursing, 41, e2-e7.

Deenadayalan, Yamini, Grimmer-Somers, Karen, Prior, Matthew, \& Kumar, Saravana. (2008). How to run an effective journal club: A systematic review. Journal of Evaluation in Clinical Practice, 14(5), 898-911.

Godley, Jenny, Glenn, Nicole, Sharma, Arya, \& Spence, John. (2014). Networks of trainees: Examining the effects of attending an interdisciplinary research training camp on the careers of new obesity scholars. Journal of Multidisciplinary Healthcare, 7, 459-470.

Gottlieb, Michael, King, Andrew, Byyny, Richard, Parsons, Melissa, \& Bailitz, John. (2018). Journal club in residency education: An evidence-based guide to best practices from the council of emergency medicine residency directors. Western Journal of Emergency Medicine, 19(4), 746-755.

Hills, Holly, \& Richards, Tara. (2014). Modeling interdisciplinary research to advance behavioural health care. The Journal of Behavioral Health Services \& Research, 41(1), 3-7.

Kingsnorth, Shauna, Taryn, Orava, Kathryn, Parker, \& Gold, Milo-Manson. (2019). From knowledge translation theory to practice: Developing an evidence to care hub in a pediatric rehabilitation setting. Disability and Rehabilitation (Advance online publication). doi: 10.1080/09638288.2018 .1514075

Lizner, Mark. (1987). The journal club and medical education: Over one hundred years of unrecorded history. Postgraduate Medical Education, 63(740), 475-478.

Ryan, Maureen, Yeung, Rachel, Bass, Michelle, Kapil, Meg, Slater, Suzanne, \& Creedon, Kate. (2012). Developing research capacity among graduate students in an interdisciplinary environment. Higher Education Research \& Development, 31(4), 557-569.

Sawleshwarkar, Shailendra, \& Negin, Joel. (2017). A review of global health competencies for postgraduate public health education. Frontiers in Public Health, 5(46), 1-12.

Wincentak, Joanne, Cheung, Stephanie, \& Kingsnorth, Shauna. (2019). Utilizing a Journal Club to Build Research Competencies in a Cross-Disciplinary Environment. Scholarly and Research Communication, 10(3): 0305337, 16 pp. 


\section{Scholarly and Research}

\section{Communication}

VOLUME 10 / ISSUE $3 / 2019$
Smith, Carolyn, Jarrett, Marcia, \& Bierer, Beth. (2013). Integrating clinical medicine into biomedical graduate education to promote translational research: strategies from two new $\mathrm{PhD}$ programs. Academic Medicine: Journal of the Association of American Medical Colleges, 88(1), 137-143.

Stucki, Gerold. (2007). Developing human and rehabilitation research part I: Academic training programs. Journal of Rehabilitation Medicine, 39(4), 323-333.

Topf, Joel, Sparks, Matthew, Phelan, Paul, Shah, Nikhil, Lerma, Edgar, Graham-Brown, Matthew, Hadariaga, Hector, Iannuzzella, Francesco, Rheault, Michelle, Oates, Thomas, Jhaveri, Kenar, \& Hiremath, Swapnil. (2017). The evolution of the journal club: From Olser to Twitter. American Journal of Kidney Diseases, 69(6), 827-836.

Vadaparampil, Susan, Simmons, Vani, Lee, Ji-Hyun, Malo, Teri, Klasko, Lynne, Rodriguez, Maria, Waddell, Rhonda, Gwede, Clement, \& Meade, Cathy. (2014). Journal clubs: An educational approach to advance understanding among community partners and academic researchers about CBPR and cancer health disparities. Journal of Cancer Education, 29(1), 122-128.

Van Diggele, Christie, Burgess, Annette, \& Mellis, Craig. (2018). Journal clubs in health professional practice. The Clinical Teacher, 16(1), 13-18.

Verderame, Michael, Freedman, Victoria, Kozlowski, Lisa, \& Mccormack, Wayne. (2018).

Competency-based assessment for the training of $\mathrm{PhD}$ students and early-career scientists. eLife, $7(\mathrm{e} 34801), 1-5$.

Wang, Jack, Power, Cheryl, Kahler, Charlene, Lyras, Dena, Young, Paul, Iredell, Jonathan, \& RobinsBrowne, Roy. (2018). Communication ambassadors: An Australian social media initiative to develop communication skills in early career scientists. Journal of Microbiology \& Biology Education, 19(1), 1-4. 